\title{
Monetary Condition Index
}

\author{
By Oumar Dicko
}

6637455

\begin{abstract}
Major Paper presented to the
Department of Economics of the University of Ottawa

in partial fulfillment of the requirements of the M.A. Degree

Supervisor: Professor Serge Coulombe
\end{abstract}

ECO 6999

Ottawa, Ontario

December 2017 


\section{Table of content}

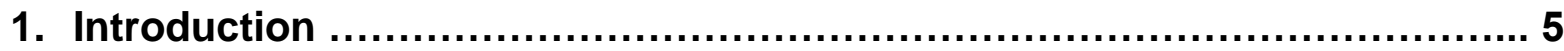

2. Monetary policy framework in Canada and transmission mechanism

2.1. Monetary policy framework in Canada .................................. 7

2.2. Transmission mechanism ............................................. 8

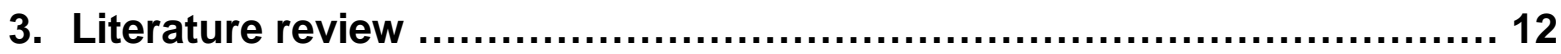

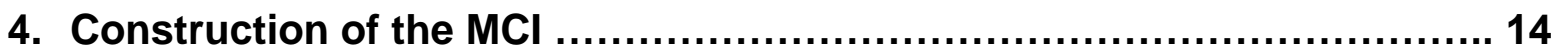

4.1. Bank of Canada usage of the $\mathrm{MCl}$ as an operational target.......... 15

5. Issue related to the construction and use of the $\mathrm{MCI}$

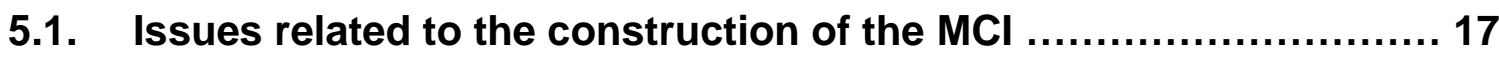

5.2. Issues related to the interpretation and movements of the $\mathrm{MCl} \ldots . .18$

6. Calculation of the $\mathrm{MCl}$ in Canada using the CERI index ...................... 19

6.1. Comparison between the Bank of Canada $\mathrm{MCl}$ and the CERI MCI .... 21

6.2. Analysis and interpretation of the CERI MCI movements ............... 23

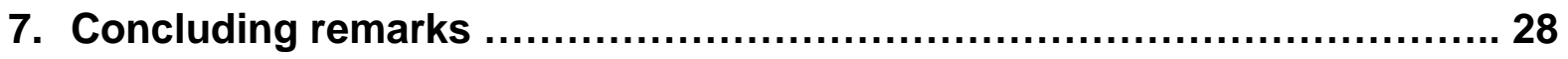




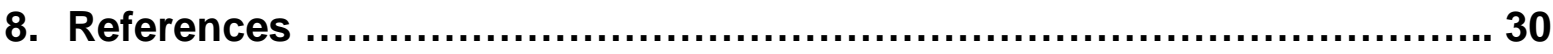




\section{Acknowledgments}

The data used in this paper have been extracted from the Statistics Canada's CANSIM tables and the Bank of Canada's Financial Market Statistics. The author thanks Professor Serge Coulombe for his supervision, assistance and comments. I would also like to thank Professor Charles Freedman for his advice at the beginning of the research project. 


\section{Summary}

The Monetary Conditions Index $(\mathrm{MCl})$ is calculated from a linear combination of the short-run interest rate and the exchange rate. It is a weighted average of short term interest rate and exchange rate vis-à-vis their value in a base period. The weights

reflect the relative effects of the respective $\mathrm{MCl}$ components on aggregate demand. The Bank of Canada used it as its operational target for monetary policy but moved away from it and stopped publishing it in 2006, mainly due to issues with the construction and interpretation of the $\mathrm{MCl}$. In this paper we have calculated the $\mathrm{MCl}$ with the new Canadian-Dollar Effective Exchange Rate Index (CERI) from 1987 to 2017. We found that the CERI MCI behaved similarly with the Bank of Canada MCI. Our analysis of the CERI MCl over the period from 1987 to 2017 led us to the conclusion that the Bank of Canada decision to move away from the $\mathrm{MCl}$ as an operational target was justified. Although, the Bank of Canada should have continued publishing the $\mathrm{MCl}$ since the $\mathrm{MCl}$ can provide timely insights on the state of monetary conditions and inflation predictions when used in conjunction with other indicators. 


\section{Introduction}

The construction of the Monetary Condition Index ( $\mathrm{MCl}$ ) was pioneered by the Bank of Canada in the 1990's and used as an operating target for monetary policy (Freedman,1994). Several other central banks incorporated the $\mathrm{MCl}$ among many other indicators of monetary conditions. For example, the Reserve Bank of New Zealand (RBNZ) adopted it in December 1996 and also used it as its operational target (RBNZ, 1996). The central banks of Norway (Norges Bank) and Sweden (Sveriges Riksbank) used the $\mathrm{MCl}$ as a device to inform about policy changes while the Bank of Finland used it internally only (Mayes and Virèn, 2000).

The Monetary Conditions Index is calculated from a linear combination of the shortrun interest rate and the exchange rate. It is a weighted average of short term interest rate and exchange rate vis-à-vis their value in a base period. The weights reflect the relative effects of the respective $\mathrm{MCl}$ components on aggregate demand. The main rationale behind this concept is that in a small open economy with flexible exchange rate and capital mobility, monetary policy affects inflation and the economy through two channels namely the interest rates and the exchange rate.

As indicated by Eika, Ericsson and Nyomen (1996), the MCl offers several key attractive features. It is simple and easy to calculate. It could provide policymakers with timely information on the economy. Freedman (1994) pointed out that a change in the index indicates how 'tight' or 'loose' monetary conditions in the economy are, relative to 
a certain reference level. It was seen as a preferred indicator than focusing solely on interest rates, given the role of the exchange rate in the transmission mechanism. The $\mathrm{MCl}$ generalizes interest-rate targeting to include the effects of exchange rates on an open economy. However, there are significant issues related to construction of the index and its movements specifically shocks affecting the exchange rate and the appropriate policy actions in response to them (Eika, Ericsson and Nyomen,1996).

The Bank of Canada (BOC) ceased to use to $\mathrm{MCl}$ as a policy guide and stopped publishing the $\mathrm{MCl}$ numbers since December 2006. The purpose of this paper is twofold, (i) to review some of the issues associated with the construction and the use of the $\mathrm{MCl}$ and (ii) to calculate the $\mathrm{MCl}$ in Canada from 1987 to 2017 with the new Canadian-Dollar Effective Exchange Rate Index (CERI) and provide some interpretation.

This paper is set out as follows, section 2 offers an overview of the monetary policy framework in Canada as well as a description of the transmission mechanism. Section 3 reviews related literature to the $\mathrm{MCl}$. Section 4 shows the methodology used to compute the $\mathrm{MCl}$. Section 5 provides some criticisms on the use and the construction of the $\mathrm{MCl}$. Section 6 outlines the calculation of the $\mathrm{MCl}$ in Canada from 1987 to 2017 using of the new Canadian-Dollar Effective Exchange Rate Index (CERI). Finally, Section 7 presents concluding remarks. 


\section{Monetary policy framework in Canada and transmission mechanism}

\subsection{Monetary policy framework in Canada}

Inflation-control target is at the core of the Canadian monetary policy framework. The Bank of Canada (BOC) goal is low, stable and predictable inflation leading to a well functioning and stable economy. The BOC adopted explicit inflation targeting first in February of 1991, in a joint announcement with the Government of Canada and is reviewed every 5 years (Bank of Canada, 2016).

The $\mathrm{BOC}$ annual inflation rate is measured by the Consumer Price Index $(\mathrm{CPI})$ at 2 per cent and within a range of 1-3 per cent around this target (Bank of Canada, 2012a). This inflation targeting objective was recently renewed by the BOC and the Government of Canada for a five-year period (Bank of Canada, 2016). Since monetary policy affects inflation with lags close to six to eight quarters and given the volatility of the prices of specific products, the Bank uses core inflation as an operational guide (Bank of Canada, 2012a). Measures of core inflation strips out some of the temporary movements in total inflation. Between 2001 and 2016 the BOC main measure of core inflation was CPIX which is derived by excluding the eight most volatile elements from the broader measure of $\mathrm{CPI}$ inflation and adjusting the remaining components for the effects of changes in indirect taxes (Bank of Canada, 2012a). 
As indicated by Macklem (2001), though core inflation and overall CPI inflation often deviate from each other over the short term, they tend to move closer in a similar way over time, revealing that the underlying inflationary trends captured by each are broadly similar.

However, the Bank of Canada ceased to use the CPIX inflation at the 2016 renewal as a main measure of core inflation and has replaced it with a set of 3 new measures: CPI common, CPI-trim and CPI-median (Bank of Canada, 2016). CPIcommon is a measure of core inflation that tracks common price changes across categories in the Consumer Price Index basket (Bank of Canada, 2016). CPI-median is a measure of core inflation corresponding to the price change located at the 50th percentile (in terms of the Consumer Price Index basket weights) of the distribution of price changes in a given month (Bank of Canada, 2016). Finally, CPI-trim is a measure of core inflation that excludes Consumer Price Index components whose rates of change in a given month are located in the tails of the distribution of price changes (Bank of Canada, 2016).

The $\mathrm{BOC}$ found that these three measures when use together tend to better capture the persistent trend in inflation movements (Bank of Canada, 2016).

\subsection{Transmission mechanism}

The BOC carries out monetary policy by influencing short term interest rates (Bank of Canada, 2012b). The main instrument for the conduct of monetary policy is the target 
for the overnight interest rate. It is the interest rate at which financial institutions lend or borrow funds on a daily basis or "overnight" to one another. By lowering or raising the target for the overnight interest rate, the bank affects other interest rates in the economy as well as the exchange rate.

The transmission mechanism is the process connecting the BOC policy instrument to the rate of inflation. It could be viewed as the channel through which monetary policy affects the economy. The BOC objective is to keep average annual inflation at 2 percent (Bank of Canada, 2012).

As illustrated in figure 1, when the Bank of Canada changes the target of the overnight interest rate, a series of events occurs. Consider a situation where the Bank anticipates inflation to rise above $2 \%$ in the near future, which can be due to a stronger US economy leading to an increase in Canadian exports and putting upward pressures on aggregate demand. The Bank appropriate response would be to tighten monetary policy, thus raising the target for the overnight interest rates.

First, other short term interest rates will rise, various commercial interest rates such as mortgages, consumer loans, as well as deposits at financial institutions. A rise in these interest rates will tend to raise the cost of borrowing and discourage spending, borrowing and investing. Second, a change in interest rates will affect the exchange rate. Higher Canadian interest rates relative to interest rates in other countries makes Canadian assets more attractive to foreign and domestic investors. The capital flow will 
increase the demand for Canadian dollar vis-à-vis other currencies, causing an appreciation of the Canadian currency.

In turn, the stronger the Canadian dollar leads to a decrease in the prices of imported goods, and making many Canadian products less competitive in foreign markets, reducing demand for them. This slows the growth of aggregate demand and put a damper on inflation.

Long term interest rates will increase and lower asset prices (bonds, stocks, houses etc) which will reduce household wealth and may discourage consumption and investments (Bank of Canada, 2012)

Lastly, the slowing growth of aggregate demand causes the level of GDP to fall below potential output. The overall demand falls below the overall capacity to supply (Output gap). This state of excess supply is eventually felt in the markets for labour and other inputs, putting downward pressures on wages and other factor prices and lowering the rate of inflation. Note that when the Bank lowers the policy interest rate, the ripple effects go in the opposite direction.

The transmission mechanism process takes time. There is a significant lag before policy actions can affect inflation and economic decisions. That is why monetary policy must be forward looking. 
Figure 1: Illustration of the transmission of monetary policy

The Bank of Canada raises the overnight rate

Other short terms and commercial rates and exchange rate rise

Long term interest rates rise and asset prices decrease

Discourage borrowing and spending Consumption expenditure, investments and net exports decrease

Aggregate demand decreases

GDP growth and Inflation decrease 
Source: Bank of Canada.ca (2012) - "Backgrounders: How Monetary Policy works: The transmission of Monetary policy."

\section{Literature review on the $\mathrm{MCl}$}

The Monetary Condition index was popular and used by many central banks and other private sectors and international organizations. Mayes and Virèn (2000) indicated that institutions other than central banks mainly used the $\mathrm{MCl}$ as an indicator of monetary policy:

Most private sector and international organizations use the MCls in an indicator role. The IMF and OECD set out tracks for the level of MCls in the main countries and measure the evolution of monetary policy against them. Mayes and Virèn (2000, p.28)

Arguments in favour of the $\mathrm{MCl}$ were its simplicity, convenience, timeliness but specifically its broadness. It combines the exchange rate and the interest rate as an indicator of monetary conditions. The Bank of Canada spearheaded the construction and the use of the $\mathrm{MCl}$ as an operational short-run target in setting monetary policy. Freedman (1995) described the role of the $\mathrm{MCl}$ at the Bank of Canada as the operational target of policy in much the same way as short-term interest rates were used in the past. Freedman (1994) also cautioned against the use of the $\mathrm{MCl}$ as a mechanical means of policy and the treatment of the index as a fundamental measure of monetary policy. As G. Thiessen, former Governor of the Bank of Canada puts it:

When we use the term monetary conditions we mean the combination of shortterm interest rate and exchange rate movements. And we aim at a path for monetary conditions which would bring about a path for aggregate demand and prices consistent with the control of inflation. Thiessen (1995, p.54).

The Reserve Bank of New Zealand (RBNZ) also used the $\mathrm{MCl}$ in a similar fashion as 
an operating target from December 1996 to March 1999 (Reserve Bank of New Zealand, 1996). The RBNZ moved away from the use of the $\mathrm{MCl}$ mainly because it created unnecessary short- term interest rates volatility and misled policy actions specifically during the Asian crisis of 1997 (Reserve Bank of New Zealand, 2000). As explained by Svensson (2001) in the Independent Review of the Operation of Monetary Policy in New Zealand:

During the $\mathrm{MCl}$ period, the Bank let exchange rate depreciation result in automatic interest rate increases with little burden of proof that those interest rate increases were warranted and in spite of the $\mathrm{MCl}$ being an unreliable indicator of the monetary policy stance. This allowed interest rate increases at the onset of the first drought and the Asian crisis in 1997/98, when a more thorough analysis of the situation may have suggested differently. This certainly contributed to unnecessary interest rate variability and may have caused some unnecessary output variability. Reserve Bank of New Zealand (2001, p.2)

Some of the literature focused both on the usefulness and the disadvantages of the MCl. Siklos (2000) explored the advantages and disadvantages of the $\mathrm{MCl}$. $\mathrm{He}$ concluded that the $\mathrm{MCl}$ can increase transparency and credibility of monetary policy but it could also increase confusion in the financial markets if they view the central bank reacting to every movement in the $\mathrm{MCl}$. That is one of the reasons why the Bank of Canada moved away from the use of the $\mathrm{MCl}$ as an operational target. As indicated by Freedman (2001) the BOC stopped using the $\mathrm{MCl}$ for three reasons. First, observers and the Canadian market tended to treat it as a precise short run target. Second, the markets started to expect an offsetting interest rate adjustment every time there was a movement in the exchange rate, whether or not such an adjustment was appropriate. Third, the central bank itself had to make a judgment on the source of the shock to the 
exchange rate and the likely persistence of the shock in order to decide on the appropriate response.

The $\mathrm{MCl}$ is a weighted average of short term interest rate and exchange rate vis-àvis their value in a base period. The weights attached to the interest rate and exchange rate are not directly observable and are model dependent. Therefore, their estimation depends on the assumptions of model used to estimate them. The weight can vary overtime and the models provide different results on the effects of interest rates and exchange rates changes on aggregate demand. But the models give similar results with regard to the ratio of effects (Freedman, 1994).

Eika, Ericsson and Nyomen (1996) provided a critical assessment of the use of the $\mathrm{MCl}$. They argued that the value of the $\mathrm{MCl}$ for conducting monetary policy is doubtful because it relies on strong assumptions including parameter constancy, cointegration,

dynamics, exogeneity, estimation uncertainty and the choice of variables. Gerlach and Smets (1996) suggest that when exchange rate disturbances determined by changes in demand and supply conditions cannot be clearly identified, the weight assigned to the exchange rate in the $\mathrm{MCl}$ should be less than the weight deriving from the exchange rate elasticity of aggregate demand.

\section{Construction of the $\mathrm{MCl}$}

The formula below, from Ericsson et al. (1999), is used to calculate the $\mathrm{MCl}$ : 


$$
M C I_{t}=\beta\left(r_{t}-r_{0}\right)+\alpha\left(e_{t}-e_{0}\right)
$$

where: $\boldsymbol{t}$ is the time index, $\boldsymbol{r}$ is the short-term interest rate (90-day commercial paper), $\boldsymbol{r}_{\boldsymbol{o}}$ is the value of the short term interest rate in the base period, $\boldsymbol{e}$ the effective exchange rate (an increase represent an appreciation of the currency) usually in logarithms, $\boldsymbol{e}_{0}$ the value of the exchange rate in the base period, $\boldsymbol{\beta}$ and $\boldsymbol{\alpha}$ are the relative weights.

The relative weights are based on empirical estimates and represent the effect of interest rate and exchange rate on aggregate demand. These weights vary per country. In the specific case of Canada, the weights ratio has been estimated to be close to $1: 3$ (Freedman, 1994). That is, a 1 percentage point in the interest rate (real or nominal) has about the same effects over time on aggregate demand as a 3 per cent change in the real or nominal effective exchange rate (Freedman, 1994). The ratio also represents the percentage of the exchange rate depreciation necessary to offset the effect on the $\mathrm{MCl}$

of a 100 basis points increase in the short-term interest rate or vice versa. The relative weights ratio $1: 3$ for Canada is based on a study by Duguay (1994) who estimated them using a vector autoregression (VAR) model, the effect of interest rate and exchange rate on aggregate demand for Canada.

\subsection{The Bank of Canada usage of the $\mathrm{MCl}$ as an operational target}

The Bank of Canada used the $\mathrm{MCl}$ as an operational target for many years before

moving away from it in 2006. Essentially, due to the fact that monetary policy actions 
affect inflation with long lags, six to 8 quarters, the $\mathrm{BOC}$ used the $\mathrm{MCl}$ to get an insight on the state of monetary conditions in the short term. The BOC calculated a projected path for the short-term interest rates, the exchange rate and obtained a projected path for the $\mathrm{MCl}$ which was consistent with the desired inflation target ( $2 \%$ in within a range of $1-3 \%$ around this target) (Freedman, 1995). If the actual $\mathrm{MCl}$ and the projected path was different in the short term, indicating an easing or tightening of monetary policy, the $\mathrm{BOC}$ would consider taking actions to bring the $\mathrm{MCl}$ back to the path consistent with the inflation target. As Thiessen (1995) explained:

When we use the term monetary conditions we mean the combination of shortterm interest rate and exchange rate movements. And we aim at a path for monetary conditions which would bring about a path for aggregate demand and prices consistent with the control of inflation. Thiessen (1995, p.54).

Freedman (1995) also reiterated this concept:

The objective of monetary policy over the next three years or so is to maintain the rate of inflation within a band of 1 to 3 per cent. The quarterly Bank of Canada staff projection takes into account such factors as the movements in foreign variables and domestic exogenous variables as well as the momentum of the economy, and sets out a path for monetary conditions that will result in the rate of inflation six to eight quarters ahead being within the Bank's target bank. .... One can think of this path as the desired or target path for monetary conditions. Freedman (1995)

But, at the same time Freedman (1995) cautioned that the process described above is not 'mechanical':

This is not to suggest that the process of assessing the prospects for the economy and for inflation is a mechanical one. A lot of judgement goes into it, and there is a lot of cross-checking against important variables such as the rate of growth of the monetary aggregates. Freedman (1995)

That is tactical, timing and economic considerations went into the decision process 
before the Bank of Canada staff decided to intervene if the 'actual' and 'desired' path of the $\mathrm{MCl}$ were different.

\section{Issues related to the construction and use of the $\mathrm{MCI}$}

The downfall of the $\mathrm{MCl}$ is due to the significant issues related to its construction and the interpretation of the observed movements in the index.

\subsection{Issues related to the construction of the $\mathrm{MCl}$}

First, the $\mathrm{MCl}$ provides a narrow view of the transmission mechanism. Short term interest rate and exchange rate are not the only factors that affects monetary conditions. Other variables such as long-term interest rate and asset prices also play a role in the transmission mechanism. Second, the relative weights used in the calculation of the $\mathrm{MCl}$ are not observed. They are based on econometric models that estimate the effect of exchange rate and interest rate on aggregate demand. Consequently, these weights highly sensitive to the model used and subject to estimation uncertainty. Furthermore, the weights are assumed to remain constant over-time. In reality, they may change. As Mervyn King (1997) argued in his speech to the Bank of England:

If the $4: 1$ rule were correct, then the appreciation of the sterling since the beginning of August was equivalent to an increase in interest rates of no less than 4.5 percentage points. I know of no one who was, or has been, arguing that interest rates needed to rise by this amount to hit inflation target. King (1997, p.225) 
Lastly, another issue in constructing the $\mathrm{MCl}$ is whether or not to express it in real or nominal terms. While real $\mathrm{MCl}$ can provide the most accurate analysis on the stance of monetary policy, in practice the BOC and other central banks have focused more on nominal $\mathrm{MCl}$ mainly because of the lags in availability of price data that are used to calculate the real exchange rate and real interest rate (Freedman,1994). The nominal $\mathrm{MCl}$ is more useful because it can be calculated on a daily basis and provide timely information to policy makers. In Canada and its major trading partners, it also tends to behave similarly to the real $\mathrm{MCl}$ in the short-run mainly because of the relatively low inflation observed since the 1990s.

\subsection{Issues related to the interpretation and the movements in the $\mathrm{MCl}$ index}

In addition to the issues related to the construction of the $\mathrm{MCl}$, there are also several practical problems with the use and the interpretation of the index. As mentioned in the introduction, the $\mathrm{MCl}$ serves as an indicator of the stance of monetary policy in a country. Canada used it as an operational target. The Bank of Canada, in light of inflation outlook would determine a desired path for the MCl (Freedman 1994). A change in the $\mathrm{MCl}$ would indicate a tightening or loosening of monetary conditions and the Bank of Canada will make the policy changes in order to offset movements in the $\mathrm{MCl}$ (Freedman, 1994). Serious difficulties arise form this overly simplistic interpretation and use of the indicator (Stevens, 1998). First, the MCl mixes together two components of different nature. The short term interest rate under the control of the central bank and the exchange rate determined by various domestic and foreign factors mostly 
independent from monetary policy. King (1997) stated that:

'...any attempt to construct a simple monetary conditions index is akin to adding together apples and oranges... One refers to an exogenous instrument of monetary policy, the other to an endogenous variable, which may be responding to changes in interest rates or to other shocks to either the domestic or overseas economy. King (1997, p.225)

Therefore, it is important to determine the nature, the source and the persistence of the exchange rate shocks before deciding the appropriate policy response. While movements in the exchange rate are quickly noticeable, it is quite challenging to determine the cause and the nature of these changes. It requires the central banks to analyze an entire range of domestic and foreign economic variables. This process is time consuming which takes away the timeliness as an attractive feature of the $\mathrm{MCl}$. According to Freedman (2001) if exchange rate changes are due to portfolio adjustments on the part of domestic or foreign investors, an offsetting of interest rate would be needed to keep the monetary conditions and the desired $\mathrm{MCl}$ unchanged. However, for other non-portfolio exchange rate shocks policy actions may not be desirable. For example, following the Asian crisis in 1997 and the significant drop in raw material prices, the Canadian dollar depreciated to cushion the economy (Freedman, 2001). Hence, exchange rate shocks cause movements in the $\mathrm{MCl}$. A misinterpretation of the nature and persistence of these shocks can mislead monetary policy.

\section{Calculation of the $\mathrm{MCl}$ in Canada from 1987 to 2017 using the CERI index}


The $\mathrm{MCl}$ is calculated following the formula below used by the Bank of Canada. In order to remain consistent with the Bank of Canada calculation of the $\mathrm{MCl}$ the base period chosen is January 1987.

The data for the Canadian-Dollar effective exchange rate (CERI) was obtained from Statistic Canada's CANSIM table 176-0081: "Monthly average foreign exchange rate in Canadian-dollars, Bank of Canada." The data for the 90-day commercial paper rate is from Statistic Canada's CANSIM table 176-0043: "Financial market statistics, Bank of Canada, percent, monthly". The Canada-US bilateral exchange rate is from Statistic Canada's CANSIM table 176-0064: "Foreign exchange rate in Canadian dollars, Bank of Canada, Monthly,". The Bank of Canada MCl is obtained from the Bank of Canada weekly financial statistics at Collection and Archives Canada. The Bank $\mathrm{MCl}$ data is only available from August 1997 to December 2006, when the Bank stopped publishing it.

\section{Formula}

$\mathrm{MCl}=(\mathrm{CP} 90-7.45)+(100 / 3) \times(\operatorname{In}(\mathrm{CERI})-\ln (92.24))$

In Jan. 1987, the $M C l=0$

CP90 = Canadian 90-day commercial paper rate

CERI= Canadian-dollar effective exchange rate index $(1992=100)$

7.45= The monthly average 90-day commercial paper rate for Jan. 1987

92.24= The monthly average CERI for Jan 1987. 
Source:

www.collectionscanada.gc.ca/eppparchive/100/201/301/bank_can_review/2006/spring/c over/en/rates/mci2.html

The formula above is the same used by the $\mathrm{BOC}$ to compute the $\mathrm{MCl}$ (Bank of Canada, 2006b). The only difference is that in this formula we use the new Canadiandollar effective exchange rate index (CERI). The CERI has replaced C-6 index since October 2006 (Bank of Canada, 2006a). It includes six foreign currencies, namely the U.S. dollar, the European Union Euro, the Japanese Yen, the U.K. Pound, the Chinese Yuan, and the Mexican Peso (Bank of Canada, 2006a).

\subsection{Comparison between the Bank of Canada $\mathrm{MCl}$ and the CERI MCI}

As indicated above, the $\mathrm{BOC} \mathrm{MCl}$ data is only available from August 1997 to December 2006. Therefore, the comparison with the CERI MCI calculated in this paper will be over the same period of time. As shown in Figure 2, both indexes behave in the same manner. They follow the same trend and move in the same direction. The difference in the indexes level is not significant but the $\mathrm{MCl}$ computed with the $\mathrm{CERI}$ is a slightly larger than the Bank of Canada's $\mathrm{MCl}$. The level of the MCls does not have any meaning in itself since it is obtained as change from an arbitrary base date. The interpretation of the changes in the $\mathrm{MCl}$ index is what matters for monetary policy. Both the $\mathrm{CERI} \mathrm{MCl}$ and the $\mathrm{BOC} \mathrm{MCl}$ show very similar changes rate over the period of comparison from 1997 to 2006 (see Figure 2 below). 
Figure 2 


\section{Bank of Canada $\mathrm{MCl} \& \mathrm{CERI} \mathrm{MCl}$}

10

8

6

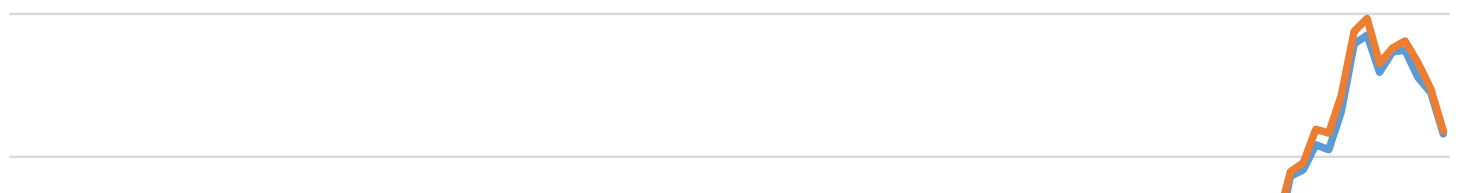

4

2

0

$-2$

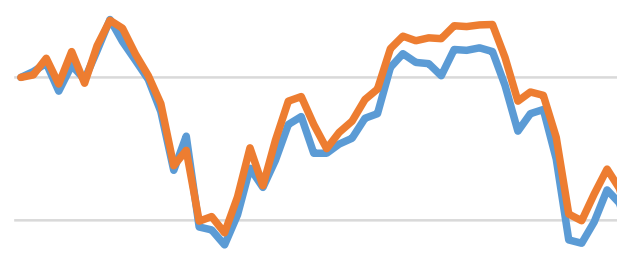

$-4$

$-6$

$-8$

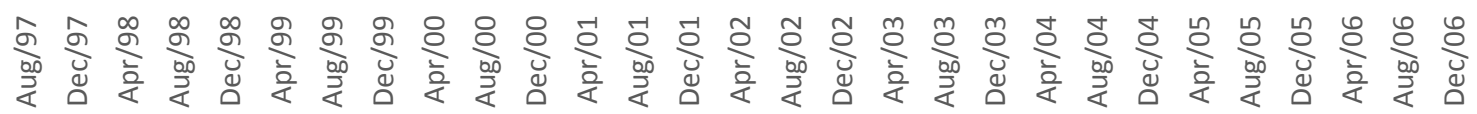

Bank of Canada MCI (Jan 1987=0) —CERI MCI (Jan 1987=0)

\subsection{Analysis and interpretation of the CERI MCI movements}


Figure 3

Canada- Nominal Monetary Condition Index (Ratio 3:1)

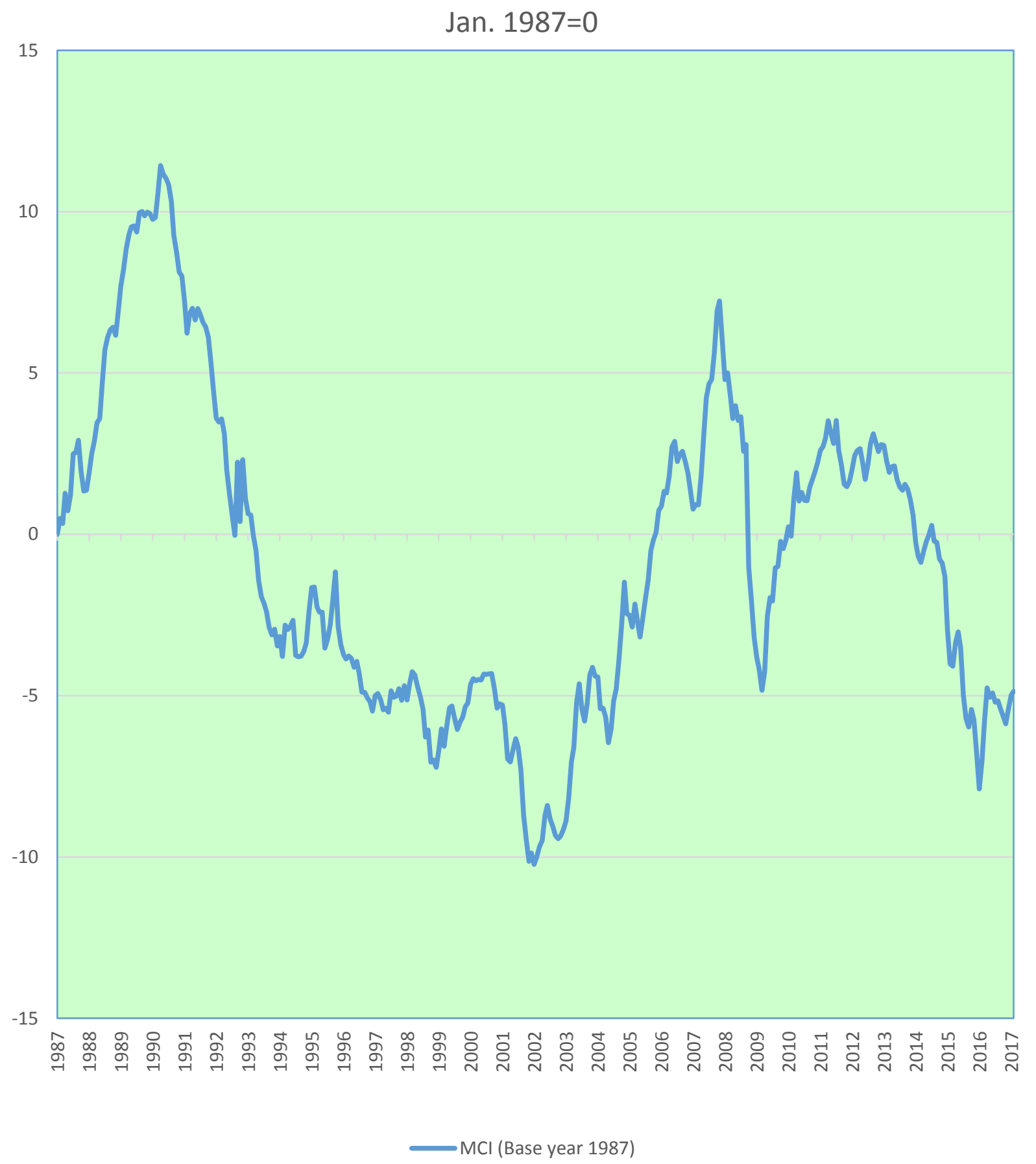

Figure 4 


\section{Interest rate \&Exchange rate variables}

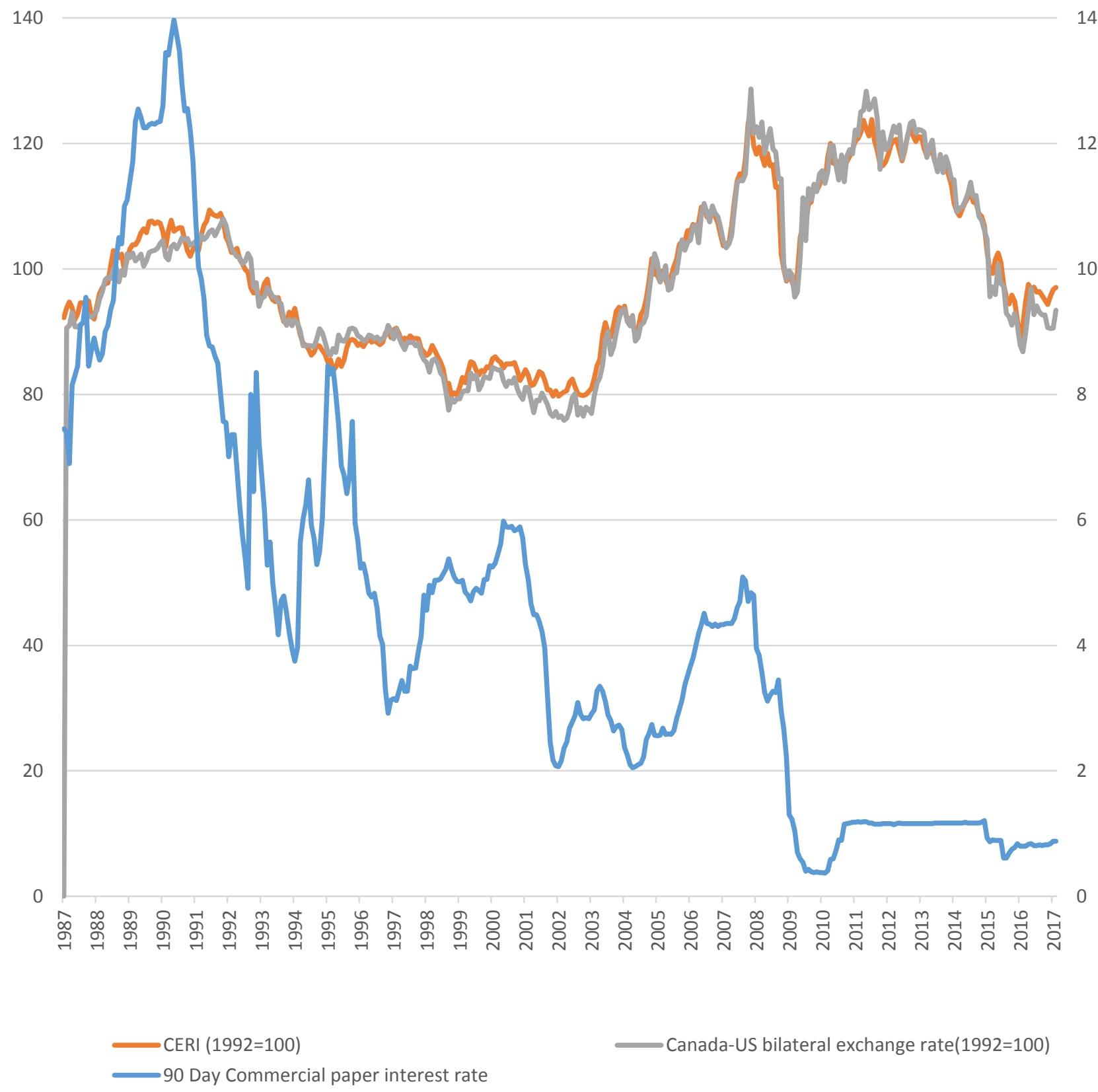


Figure 3 shows the evolution of the Canadian MCI from 1987 to 2017, and Figure 4 depicts the evolution of the interest rate and exchange rate over the same period.

From 1987 to July 1990, as indicated on Figures 3 and 4 there is an important increase in the $\mathrm{MCl}$ and the interest rate. The interest rate grew from 7.45 to 13.47 per cent while the CERI exchange rate only appreciated by 13.46 percent. Therefore, considering the 1:3 weights ratio in the $\mathrm{MCl}$ formula. The growth of interest rate during this period increased the $\mathrm{MCl}$ by 6 points while the exchange rate appreciation raised the $\mathrm{MCl}$ by 4.5 points. Consequently, $57 \%$ of the $\mathrm{MCl}$ increase is due to the interest rate while $43 \%$ is associated to the exchange rate appreciation. The majority of the change in the $\mathrm{MCl}$ during that period is explained by the changes in the interest rate. The hike in the $\mathrm{MCl}$ points to the tightening of monetary policy. Indeed, during this time the Bank of Canada maintained restrictive monetary policy which was designed to reduce inflation (Bank of Canada, 2001a).

From August 1990 to December 2001, Figure 3 shows a significant fall in $\mathrm{MCl}$. A decrease in the $\mathrm{MCl}$ indicates a loosening in monetary conditions. Over the period from, the 90 -day commercial paper interest rate significantly dropped from $12.95 \%$ to $2.08 \%$ (Figure 4) while the Canadian-Dollar Effective Exchange rate (CERI) also depreciated by $24 \%$ (Figure 4 ). Given these results, $56 \%$ of the fall in the $\mathrm{MCl}$ is due to the interest rate and $44 \%$ to the exchange depreciation. Therefore, the changes in the $\mathrm{MCl}$ over the period are mainly explained by the movements in the interest rates but the exchange rate depreciation also played a considerable part. The Bank of Canada reduced the target interest rate to cope with the recession that began in the second quarter of 1990 
and continued to do so over the entire period to encourage recovery (Bank of Canada, 2001b). Some factors contributing to the 1990 recession included the restrictive monetary policy of the BOC which was designed to reduce inflation, a slowdown in the US economy, and federal tax increases to reduce the national debt (Wilson; Dungan; and Murphy, 1994). Although slow, most of the recovery from the 1990 recession was export driven. The depreciation of the Canadian dollar and the US economy recovering both contributed to the recovery in Canada (Wilson; Dungan; and Murphy, 1994).

From Jan 2002 to December 2007, the results in Figure 3 show an increase in the $\mathrm{MCl}$, revealing the tightening of monetary conditions. The commercial paper interest rate remained fairly stable for most of the period between $2 \%$ and $3 \%$ but in the last quarter of 2005, it increased from $3 \%$ to close to $5 \%$ (Figure 4). The CERI on the other hand significantly appreciated over the same period by 34\% (Figure 4). Therefore, $21 \%$ of the change in the $\mathrm{MCl}$ is associated to the interest rate while $79 \%$ is explained by the appreciation of the exchange rate. As a result, most of the changes in $\mathrm{MCl}$ in this timeframe are explained by the exchange rate movements. The BOC raised its target overnight rate from 3 per cent in the second quarter of 2005 to 4 1/4 in December 2007. The rationale behind the increase in interest rate was to cope with inflationary pressures on the economy due to the significant increase in energy and oil prices that started in late 2000 (Bank of Canada, 2005). As indicated above, the Canadian Effective Exchange rate (CERI) has appreciated by $34 \%$ and the bilateral exchange CAD/USD has appreciated by 38\% (Figure 4). According to Coulombe, Beine and Bos (2012), the significant increase in commodity and oil prices has led to a resource boom in Canada 
from 2002 to 2008 . This is particularly illustrated by the considerable development of the oil sands in Alberta over the same period. As explained by Coulombe, Beine and Bos (2012), the remarkable development of the Oil sands in the Province of Alberta is mainly due technology advances reducing the cost of extraction and the rise of oil and energy prices. However, oil prices have quickly fallen due to the financial crisis that started in the first quarter of 2008 .

From Jan 2008 to July 2009, the MCl dropped significantly, which indicates a loosening of monetary conditions. The interest rate sunk from $4 \%$ to $0.4 \%$ and the CERI exchange depreciated by $9.5 \%$ (Figure 4). Consequently, the interest rate decreased the $\mathrm{MCl}$ by $53 \%$ while the exchange rate lowered the $\mathrm{MCl}$ by $47 \%$. The cope with the 'Great Recession' in 2008, the Bank of Canada drastically lowered the overnight interest rate going from 4.25 per cent to 0.25 per cent in the span of 5 quarters to cushion and stimulate to economy. The BOC maintained the overnight rate at the lower bound of 0.25 per cent until the second quarter of 2010 to encourage recovery. Canada was the first country in the $\mathrm{G} 7$ to raise the policy interest rate a year after the global recession in the second quarter of 2010 . The $\mathrm{BOC}$ first raised it from 0.25 per cent to 0.5 and a month after 0.75 . The Bank of Canada explained that economic recovery was proceeding in Canada more rapidly than projected. The $\mathrm{MCl}$ (Figure 3) increased at the same time, showing a tightening of monetary conditions. The overnight policy interest rate was raised again to 1 per cent and kept at this level until the first quarter of 2015 . From 2014 to 2017 , the $\mathrm{MCl}$ decreased. The interest rate remained fairly constant over the period at $1.16 \%$, dropping to $0.6 \%$ in August 2015 and rising back to $0.9 \%$ in 2017 . 
The CERI exchange rate on the other end depreciated by $13.4 \%$. Therefore, $94 \%$ of the movements in the $\mathrm{MCl}$ over that period is due to the exchange rate depreciation while only $6 \%$ is caused by the interest rate. Commodities and oil prices have dropped significantly in 2014 , following the same trend until 2017 . The BOC lowered to the overnight rate to 0.75 and to 0.5 per cent in second quarter of 2015 , saying the sharp drop in oil prices will have a negative impact on growth and inflation. The Bank of Canada also voiced concern about the low outlook for growth in Canada.

The analysis above shows that the interpretation of changes in the index should be done with particular care. Both, interest rate and exchange rate movements affect $\mathrm{MCl}$. It is sometimes difficult to disentangle the changes in the index caused by the interest rate or the exchange rate, in order to make proper monetary policy decisions. The $\mathrm{MCl}$ could be a good indicator of monetary conditions in a country when used in conjunction with other indicators.

\section{Concluding remarks}

An $\mathrm{MCl}$ is an appealing operational short-run target for monetary policy. It has many attractive features: it is simple to calculate, timely and it broadens an interest-rate target to incorporate effects of the exchange rate in an open economy. It serves as a good indicator among others of the stance of monetary policy but could not be solely relied upon in the conduct of monetary policy. This paper highlighted the $\mathrm{MCl}$ shortcomings associated with the construction and the use of the index. The weights of the $\mathrm{MCl}$ components, interest rate and exchange are estimated and are model 
dependent. They can vary significantly depending of the methodology and model used, so they are subject to estimation uncertainty. Also, the movements in the index are difficult to interpret and to disentangle between the effects of interest rates and exchange rate. The nature, the source and the persistence of the exchange rate shocks have to be determined before making policy decision when the $\mathrm{MCl}$ is used as an operational target. This process takes time and can involve analysis of a broad range of data and relevant information, taking away timeliness and simplicity as attractive feature of the $\mathrm{MCl}$. Consequently, the Bank of Canada decision to move away from the use of the $\mathrm{MCl}$ as an operational target was justified. However, this paper also shows that the $\mathrm{MCl}$ can provide complementary, timely and insightful information on monetary conditions and inflation predictions in the short term for monetary policy decisions but should be used with limitation and caveats. Any indication of tightening or loosening as conveyed by movements in the $\mathrm{MCl}$ must be considered alongside a broader range of other indicators. 


\section{$\underline{\text { References }}$}

Bank of Canada. (2001a) 'Canada's economic future: What we've learned from the 1990s' Remarks by Gordon Thiessen.

Bank of Canada. (2001b) 'Press releases' www.bankofcanada.ca/press-releases

Bank of Canada. (2006a) 'A new effective exchange rate index for the Canadian-dollar'. Bank of Canada Review, Autumn 2006

Bank of Canada. (2006b) 'Monetary Policy Indicators-MCl'

www.collectioncanada.gc.calmci

Bank of Canada. (2016) 'Renewal of Inflation Control target' Background information www.bankofcanada.ca/wp-content/uploads/2016/10/background_nov11.pdf

Bank of Canada. (2012) 'Monetary Policy' Backgrounders

www.bankofcanada.ca/wp-content/uploads/2010/11/monetary_policy.pdf

Bank of Canada. (2012) 'Backgrounders-How monetary policy works: the transmission mechanism' www.bankofcanada.ca/wp-content/uploads/2010/11/how_monetary_policy_works.pdf

Beine, M., Bos, C., Coulombe, S. (2012) 'Does the Canadian Economy suffer from Dutch disease'. Resource and Energy Economics 34, pp. 468-492

Duguay, P. (1994) 'Empirical Evidence on the Strength of the Monetary Transmission Mechanism in Canada: An Aggregate Approach'. Journal of Monetary Economics, 33(1), pp. 39-61.

Eika, K. H., N. R. Ericsson, and R. Nymoen. (1996) 'Hazards in Implementing a Monetary Conditions Index'. Oxford Bulletin of Economics and Statistics, 58, 4, pp. 76590 .

Ericsson, N. R., E. S. Jansen, N. A. Kerbeshian, and R. Nymoen (1999) 'Understanding a Monetary Conditions Index'. International Finance Discussion Paper,Board of Governors of the Federal Reserve System, Washington, D.C

Freedman, C. (1994) 'The use of indicators of Monetary Conditions Index in Canada' in Balino, T.J.T. and Cattarelli, C. (Eds), Frameworks for Monetary Stability, International Monetary Fund, Washington, DC, pp. 458-76

Freedman, C. (1995) 'The Role of Monetary Conditions and the Monetary Conditions Index in the Conduct of Policy.' Bank of Canada Review, Autumn: 53-59 
Freedman, C. (2001) 'Recent developments in the framework for the conduct of monetary policy in Canada' Canadian Business Economics, Feb 2001, Vol.8(3), pp.3-6

Gerlach, S. and Smets, F. (1996) 'MCls and Monetary Policy in Small Open Economies under Floating Rates'. European Economic Review 44 (2000) pp. 1677-1700

King, M. (1997) 'Monetary policy and the exchange rate' Bank of England Quarterly Bulletin; May 1, 1997, Periodicals Archive Online pg. 225

Macklem, T. (2001) 'A New Measure of Core Inflation.' Bank of Canada Review Autumn:

$3-12$

Mayes. D and Virèn.M. (2000) 'Exchange rate considerations in a small open economy: A critical look at the $\mathrm{MCl}$ as a possible solution'

Reserve Bank of New Zealand. (1996) 'Monetary Policy Statement' December 1996

Reserve Bank of New Zealand. (2000) 'Independent review of the operation of monetary policy', September 2000.

Reserve Bank of New Zealand. (2001) 'Independent review of the operation of monetary policy', February 2001.

Siklos, P. (2000) 'Is the $\mathrm{MCl}$ a useful signal of monetary policy conditions? An empirical investigation'. International Finance, Vol. 3 No. 3, pp. 413-37.

Stevens, G. (1998) 'Pitfalls in the Use of Monetary Conditions Indexes', Reserve Bank of Australia, speech July 1998.

Thiessen, G. G. (1995) 'Uncertainty and the Transmission of Monetary Policy in Canada- L'Incertitude et la Transmission de la Politique Monétaire au Canada', Bank of Canada Review - Revue de la Banque du Canada, Summer, pp. 41-58.

Wilson, T., Dugan, P., and Murphy, S. (1994) 'The sources of the recession in Canada: 1989-1992', Canadian Business Economics, Winter 1994 